\title{
Botulinum toxin type A wear-off phenomenon in chronic migraine patients: how long does the maximum efficiency last?
}

\author{
O fenômeno do encurtamento do efeito da toxina botulínica tipo \\ A em pacientes com migrânea crônica: quanto tempo dura a \\ eficiência máxima?
}

Aygul Tantik PAK', Ismet ÜSTÜN², Yildizhan SENGUL ${ }^{1}$

\begin{abstract}
Background: Botulinum toxin Type A (BoNTA) is a successful treatment for chronic migraine prophylaxis. Objective: We aimed to evaluate the monthly change of effectiveness of BoNTA treatment. Methods: A total of 80 patients (70 females and 10 males) with chronic migraine were included. In our study protocol, we applied to $155 \mathrm{U}$ across 31 fixed-sites and if the patient had pain, $40 \mathrm{U}$ dose injections were applied across 8 specific head/neck muscle areas. Headache days and analgesic intake were noted before the BoNTA injection and during the interviews at the first, second, and third months after the BoNTA injection. Results: The mean age was $37.59 \pm 7.60$ and $87.5 \%$ of the patients were female. The mean number of headache days/month before BoNTA was 18.95 \pm 2.69 , decreasing to $10.55 \pm 3.15$ days/month in the first month ( $p<0.001$ ), $9.31 \pm 2.43$ days/month in the second month ( $p<0.001$ ), and increased to $11.97 \pm 3.27$ days/month in the third month ( $p<0.001)$. The mean analgesic intake before BoNTA was 11.48 \pm 4.68 tablets/month, while it decreased to $6.53 \pm 2.72$ tablets/month in the first month ( $p<0.001)$ and $5.40 \pm 2.46$ tablets/month in the second month ( $p<0.001$ ). In the third month, it was $5.85 \pm 2.59$ tablets/month ( $p<0.001)$. There was a significant increase in pain medication use from the second to the third month $(p<0.001)$. Conclusion: In our study, there was a significant reduction in analgesic intake and headache days in the first and second months after BoNTA injection, and an increase was observed in the third month.
\end{abstract}

Keywords: Headache; Migraine Disorders; Botulinum Toxin, Type A.

\section{RESUMO}

Antecedentes: A toxina botulínica Tipo A (BoNTA) é um tratamento de sucesso para a profilaxia da migrânea crônica. Objetivo: Nosso objetivo foi avaliar a mudança mensal da eficácia do tratamento com BoNTA. Métodos: Um total de 80 pacientes (70 mulheres e 10 homens) com migrânea crônica foi incluído. Em nosso protocolo de estudo, aplicamos $155 \mathrm{U}$ em 31 locais fixos e, se o paciente sentisse dor, injeções de dose de 40 U foram aplicadas em 8 áreas musculares específicas da cabeça/pescoço. Dias de cefaleia e ingestão de analgésicos foram anotados antes da injeção de BoNTA e durante as entrevistas no primeiro, segundo e terceiro meses após a injeção de BoNTA. Resultados: A média de idade foi $37,59 \pm 7,60$ e 87,5\% dos pacientes eram do sexo feminino. O número médio de cefaleias dias/mês antes da BoNTA foi de 18,95 $\pm 2,69$ dias/mês, diminuindo para 10,55 $\pm 3,15$ dias/mês no primeiro mês ( $p<0,001$ ), 9,31 $\pm 2,43$ dias/mês no segundo mês ( $p<0,001$ ), e aumentou

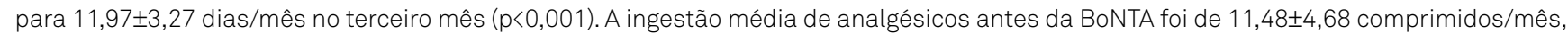
enquanto diminuiu para 6,53 $\pm 2,72$ comprimidos/mês no primeiro mês ( $p<0,001)$ e 5,40 $\pm 2,46$ comprimidos/mês no segundo mês ( $p<0,001$ ). No terceiro mês, era de 5,85 $\pm 2,59$ comprimidos/mês ( $p<0,001)$. Quando comparados o segundo e o terceiro mês, observou-se aumento significativo do uso de analgésicos do segundo para o terceiro mês ( $p<0,001)$. Conclusão: Em nosso estudo, houve redução significativa da ingestão de analgésicos e dos dias de cefaleia no primeiro e segundo meses após a injeção de BoNTA, e aumento no terceiro mês.

Palavras-chave: Cefaleia; Transtornos de Enxaqueca; Toxinas Botulínicas Tipo A.

${ }^{1}$ Gaziosmanpasa Training and Research Hospital, Department of Neurology, Istanbul, Turkey.

${ }^{2}$ Bezmialem Foundation University Hospital, Department of Neurology, Istanbul, Turkey.

ATP (D) https://orcid.org/0000-0002-7414-3800; IS (D) https://orcid.org/0000-0001-5745-5485;YS (D) https://orcid.org/0000-0002-5087-9944

Correspondence: Aygul Tantik Pak; Email: aa.aygultantik@hotmail.com.

Conflict of interest: There is no conflict of interest to declare.

Authors' contributions: IU, YS: acquisition of data; ATP, YS, IU: conception or design of the study and acquisition/interpretation of data; ATP, YS, IU: conception or design of the study. All authors made a substantial contribution to manuscript development, gave final approval of the manuscript for submission, and agreed to be accountable for all aspects of the work.

Received on November 23, 2020; Received in its final form on February 16, 2021; Accepted on February 19, 2021. 


\section{INTRODUCTION}

Migraine is one of the most common neurological diseases $^{1,2}$. The prevalence of migraine for the adult population is between 3.3 and $21.9 \%$ for women and between 0.7 and $16.1 \%$ for men $^{2}$. Migraine is a neurological disorder characterized by recurrent, pulsating headache attacks, and symptoms such as aggravation by or avoidance of routine physical activity, photophobia, phonophobia, nausea, and vomiting33. Most migraineurs have moderate or severe pain and $75 \%$ have a reduced ability to function normally during the headache attacks. ${ }^{4}$. Hence it often affects patients' productivity and leads to loss of workdays ${ }^{5}$. Migraine can have episodic and chronic forms ${ }^{6}$. Chronic migraine is a migraine subtype in which a headache is present for at least 15 days per month for at least 3 months, with a migraine character for at least eight days? Chronic migraine occurs in around $2 \%$ of the population and chronicity rate of episodic migraine is around $3 \%$ per year. Therefore, effective treatment is very important for the quality of life of patients 9 . In addition to avoiding migraine triggers, treatment includes medications and non-medication treatments to prevent and stop migraine attacks 9 .

Botulinum toxin Type A (BoNTA) injection is a successful treatment for chronic migraine ${ }^{10,11,12}$. Mediators such as glutamate, calcitonin gene-related peptide, and substance $\mathrm{P}$ released from the sensory nerve terminals cause pain in migraine pathophysiology. BoNTA is thought to reduce peripheral sensitization and neurogenic inflammation by reducing the secretion of these substances and indirectly suppressing central sensitization. BoNTA inhibits the release of acetylcholine in presynaptic vesicles, leading to dosedependent reversible paralysis. The effect starts 2-3 days after application, reaches a maximum in 2 weeks and disappears within 2-4 months with axonal sprouting ${ }^{10,11}$.

In this study, we aimed to determine the benefit of BoNTA on the monthly changes in headache days and analgesic intake in chronic migraine patients who underwent BoNTA for the first time.

\section{METHODS}

This study was designed as an observational prospective cohort study. The study protocol was conducted in accordance with the ethical principles stated in the 'Declaration of Helsinki' and was approved by the Ethical Committee of the Gaziosmanpasa Training and Research Hospital. Informed consent was obtained from the participants after the nature of the procedures had been fully explained.

A total of 80 patients (70 females, 10 males) with chronic migraine who were admitted to the neurology outpatient clinic of Bezmialem Foundation University Hospital were included in the study between 2017 and 2018. Inclusion criteria were being between 18 and 65 years old and diagnosed with chronic migraine according to the International Classification of Headache Disorder, ICHD-III-B ${ }^{3}$ classification. Exclusion criteria were prior BoNTA injection, pregnancy, additional headache types other than migraine. Analgesic overuse was defined as the use of headache medication on more than 15 days per month, for more than 3 months. Patients with headache analgesic overuse $(n=27)$ were also included in the study. Prophylactic treatments of the patients were not changed during the study (Table 1). Patients were informed about the headache diary and were instructed on to fill them out. Before the procedure, monthly headache days and analgesic intake were recorded. A minimum of 155 and a maximum of 195 units of BoNTA across 31 fixed-sites were applied to the patients in the regions specified in the PREEMPT ${ }^{9}$ studies. If the patient had pain, $40 \mathrm{U}$ additional doses across 8 head/neck muscle areas was administered. After the procedure, the number of headache days and analgesic intake were recorded monthly for 3 months. Visits were scheduled across intervals (before BoNTA injection - the first visit, after one month from BoNTA injection - second visit, after two months from BoNTA injection - the third visit, after three months from BoNTA injection - fourth visit). BoNTA response was obtained by calculating

Table 1. Sociodemographic and clinical data of all patients.

\begin{tabular}{|c|c|}
\hline & All patients \\
\hline Age (years) & $37.59 \pm 7.60$ \\
\hline \multicolumn{2}{|l|}{ Sex, \% (n) } \\
\hline Female & $87.5 \%(n=70)$ \\
\hline Male & $12.5 \%(n=10)$ \\
\hline Duration of diagnosis (years) & $14.30 \pm 6.36$ \\
\hline \multicolumn{2}{|l|}{ Treatments } \\
\hline SSRI or SNRI & $25 \%(n=20)$ \\
\hline Topiramat+SNRI & $23.8 \%(n=19)$ \\
\hline Topiramat & $18.8 \%(n=15)$ \\
\hline SNRI+amitriptilin & $7.5 \%(n=6)$ \\
\hline Propranolol+amitriptilin & $5 \%(n=4)$ \\
\hline Valproicacid+Topiramat & $5 \%(n=4)$ \\
\hline Flunarazin & $4 \%(n=2)$ \\
\hline Amitriptyline & $2.5 \%(n=2)$ \\
\hline Flunarazin+propranolol & $1.3 \%(n=1)$ \\
\hline No medication & $3.8 \%(n=3)$ \\
\hline \multicolumn{2}{|l|}{ Medication overuse } \\
\hline Yes & $33.8 \%(n=27)$ \\
\hline No & $66.3 \%(n=53)$ \\
\hline
\end{tabular}

SNRI: selective norepinephrine reuptake inhibitor; SSRI: selective serotonin reuptake inhibitors. 
separately for each patient according to the change in number of headache days by comparing to the second month (8 weeks - third visit) - with the first visit. Patients whose headaches did not decrease or increased compared to the previous month were considered unresponsive. We also looked for the patients whose headache days continued to decrease after three months (at the fourth visit -12 weeks).

\section{Statistics}

The IBM SPSS Statistics Version 20.0 package program was used for statistical analysis. Categorical measurements were evaluated as numbers and percentages, and the numerical measurements as mean and standard deviation (median and minimummaximum are provided) and descriptive statistical methods were used. Under the assumption that the data were distributed normally, one-sample Student's $t$-tests were utilized for the comparison of numeric data. Multiple regression analysis was used to assess related factors with BoNTA response. A p-value of less than 0.05 was considered statistically significant.

\section{RESULTS}

The mean age of the 80 patients included in the study was $37.59 \pm 7.60$ years, and $87.5 \%(n=70)$ of the patients were female and $12.5 \%(n=10)$ were male. The most common treatments of the patients were as follows: $25 \%(n=20)$ was taking selective serotonin reuptake inhibitors or selective norepinephrine reuptake inhibitor, 23.8\% ( $n=19)$ was taking Topiramate+selective norepinephrine reuptake inhibitor, and $18.8 \%(\mathrm{n}=15)$ was taking Topiramate. Medication overuse was present in $33.8 \%(n=27)$ of the patients (Table 1$)$.

The mean number of headache days/month before BoNTA was $18.95 \pm 2.69$, it decreased to $10.55 \pm 3.15$ days/month in the first month, 9.31 \pm 2.43 days/month in the second month, and increased to $11.97 \pm 3.27$ days/month in the third month. The number of headache days before BoNTA was significantly different than the number of headache days at each of the 1 st $(\mathrm{p}<0.001)$, 2nd $(\mathrm{p}<0.001)$ and 3rd months after BoNTA $(p<0.001)$. The number of headache days changed significantly $(\mathrm{p}<0.001)$ when the first and second months $(\mathrm{p}<0.001)$, 1st and 3rd months $(\mathrm{p}<0.001)$, and 2nd and 3rd months were compared (Table 2, Figure 1).

The mean monthly analgesic intake before BoNTA was $11.48 \pm 4.68$ tablets, while it decreased to $6.53 \pm 2.72$ tablets/ month in the first month and 5.40 \pm 2.46 tablets/month in the second month. In the third month, it increased to $5.85 \pm 2.59$ tablets/month. Parallel to the number of headache attacks, the analgesic intake prior to BoNTA administration was statistically significant when compared with each of the 1st $(\mathrm{p}<0.001), 2 \mathrm{nd}(\mathrm{p}<0.001)$, 3rd months after BoNTA $(\mathrm{p}<0.001)$. When the second and third months $(\mathrm{p}<0.001)$ were compared, there was a significant increase in the analgesic intake at the third month $(\mathrm{p}<0.001)$, but it was still

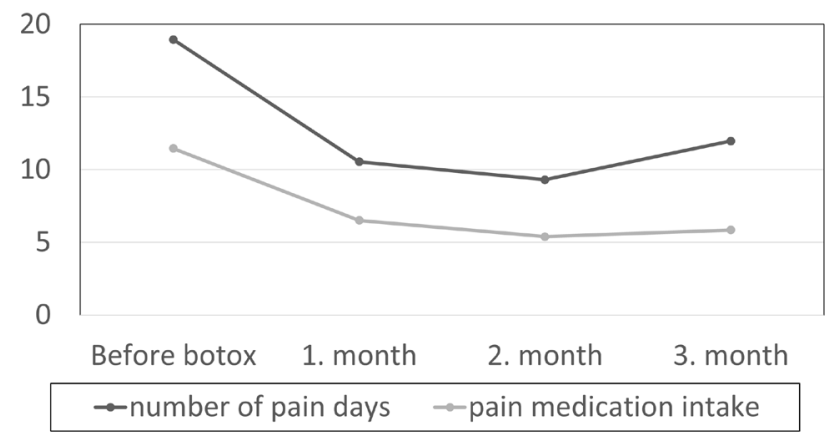

Figure 1. Monthly change of the number of painful days and pain medication intake with Botulinum toxin Type A treatment.

Table 2. Monthly change of the number of headache days and analgesic intake with Botulinum toxin Type A treatment.

\begin{tabular}{|c|c|c|c|c|}
\hline & \multicolumn{4}{|c|}{ Number of headache days } \\
\hline & Before BoNTA & 1 month & 2 months & 3 months \\
\hline Days/month & 18.95 & 10.55 & 9.31 & 11.97 \\
\hline Standard deviation & 2.69 & 3.15 & 2.43 & 3.27 \\
\hline \multirow[t]{3}{*}{$p$} & & $p<0.001 * *$ & $p<0.001 * \star$ & $p<0.001 * *$ \\
\hline & \multicolumn{4}{|c|}{ Analgesic intake } \\
\hline & Before BoNTA & 1 month & 2 months & 3 months \\
\hline Tablets/month & 11.47 & 6.52 & 5.40 & 5.85 \\
\hline Standard deviation & 4.68 & 2.72 & 2.46 & 2.59 \\
\hline$p$ & & $p<0.001^{\star \star \star *}$ & $p<0.001^{\star \star \star}$ & $p<0.001 * \star \star *$ \\
\hline
\end{tabular}

BoNTA: Botulinum toxin Type A; *one sample Student's t-test; **the number of headache days before BoNTA was compared with the number of headache days at the $1^{\text {st }}, 2^{\text {nd }}$, and $3^{\text {rd }}$ month after BoNTA; $* \star \star$ the mean monthly analgesic intake before BoNTA was compared with the mean monthly analgesic intake at the $1^{\text {st }}, 2^{\text {nd }}$, and $3^{\text {rd }}$ month after BoNTA. 
significantly lower than the analgesic intake before and at the first month after BoNTA $(\mathrm{p}<0.001)$ (Table 2, Figure 1).

The percentage of BoNTA responsive patients was $97.5 \%$. The mean reduction rate in the number of headache days at the third visit was $50.49 \pm 14.47 \%$. The reduction of headache days at the second visit continued in $53.8 \%$ of patients at the third visit, and $26.3 \%$ of the patients had an increase in the number of headache days compared to the second visit with the third visit; $20 \%$ of the patients had no change in the number of days with headache. Reduction of headache days was found to continue in $8.75 \%(n=7)$ of the patients in the 3rd month (fourth visit), indicating the headache days of these seven patients continued to decrease in each visit (second, third, and fourth visits). In the patients whose reduction of headache days continued at the forth visit compared with the rest, monthly intake of analgesic tablets (before BoNTA injections) was different between groups $(\mathrm{p}=0.038)$ (Table 3 ). This relationship was also present in the multiple regression analysis.

\section{DISCUSSION}

We investigated the effectiveness of BoNTA treatment in patients with chronic migraine who underwent BoNTA for the first time and determined the monthly variability of analgesic intake and number of headache days after the injections. Almost all of our patients were BoNTA-responsive, with a significant reduction of analgesic intake and headache days in the first and second months after BoNTA treatment. However, a decrease of the positive effect was observed at the third month (Figure 1). In addition, the reduction of headache days decreased month-to-month. The higher monthly analgesic intake was a negative factor for the continuation of the decrease in the number of headache days.

Zidan et al. studied 38 chronic migraine patients who underwent 155 to $195 \mathrm{U}$ BoNTA treatment in the regions recommended in the PREEMPT study, similar to our study, and they monitored the number and severity of headache days and number of weekly painkiller intake. They observed that the number of headache days increased at the 8-week evaluation ${ }^{13}$. Markedly, that study had a very similar design and objective, and resulted in similar findings to our study.

Recently, in a retrospective study of 112 patients who had at least 30\% BoNTA response, full BoNTA effect occurred in weeks 5 to 8 . An increase in headache days was reported at the 12th and 13th weeks compared to the 5th and 8th weeks ${ }^{14}$. Our study was designed prospectively and follow-ups were done monthly, which allowed us to observe the monthly change in headache and analgesic intake. Unlike the aforementioned study, it was found that the wear-off effect appeared earlier. These results may be due to the difference in inclusion criteria, as they only included BoNTA-responsive patients.

In a previous retrospective study, authors accepted a $50 \%$ reduction in the number of headache days at week 12 as a complete response and reported that $47.1 \%(91 / 193)$ of their patients achieved a complete response. With these results, they emphasized that the treatment dose should be increased in patients with decreased BoNTA response ${ }^{15}$. In a study evaluating the BoNTA response in 143 patients, which considered wear-off as an increase in the number of headache days and use of painkillers during the 6-week follow-up, the authors found a wear-off rate of $62.9 \%^{16}$. These studies were retrospective and had different inclusion criteria, and the BoNTA response was handled differently in each study.

The interval for BoNTA injection in the management of chronic migraine is 12 weeks (78-84 days). Khan et al. studied 98 chronic migraine patients and their results also supported the notion that the 12-week injection protocol may not provide a sustained effect in all patients, explaining the failure in BoNTA response ${ }^{17}$.

In PREEMPT 1 and PREEMPT 2 studies of 1384 patients diagnosed with chronic migraine, BoNTA treatment and placebo groups were compared (24 weeks of double-blind assessment) and it was proven that BoNTA treatment was an effective, safe, and well-tolerated prophylactic agent for the treatment of chronic migraine. In these studies, which included headache patients with painkiller abuse, additional optional $40 \mathrm{U}$ BoNTA injections were applied to 8 points in

Table 3. Evaluation of possible related factors with continuation of reduction of headache days.

\begin{tabular}{lccc}
\hline & $\begin{array}{c}\text { BoNTA response } \\
(n=7) \\
(\text { Mean rank })\end{array}$ & $\begin{array}{c}\text { No BoNTA response } \\
(n=73) \\
\text { (Mean rank) }\end{array}$ & 41.79 \\
\hline Age (years) & 27.00 & 41.23 & 0.107 \\
Headache days before BoNTA (day/month) & 32.93 & 42.18 & 0.363 \\
Analgesic intake before BoNTA (pieces/month) & 23.00 & 41.42 & 0.036 \\
Duration of diagnosis (years) & 32.86 & 40.39 \\
\hline Duration of prophylactic treatment (years) & 41.64 & 0.890 \\
\hline
\end{tabular}

BoNTA: Botulinum toxin Type A; *Mann-Whitney U test. 
head and neck muscles. Thus, a minimum dose of $155 \mathrm{U}$ and a maximum dose of $195 \mathrm{U}$ BoNTA was administered to each patient. At the end of 24 weeks, the number of headache attacks was assessed primarily in PREEMPT 1, and the number of headache days was assessed in PREEMPT 2, and a significant decrease in the number of headache days in those who received BoNTA treatment was observed compared to those receiving placebo therapy $(\mathrm{p}=0.006 ; \mathrm{p}<0.01)^{18,19}$. These results were very close to our study in which patients received 155 to 195 U BoNTA injections. There was a significant decrease in analgesic intake and headache days in the 1st and 2nd months. These results were very close to our study. However, in the PREEMPT study, the injection was repeated at the 12th week and the follow-up was continued, whereas, in our study, we stopped the follow-up at the 12th week.

This study should be considered within the context of several limitations. First, there was no placebo group. Therefore, as in all previous studies, the placebo effect could not be excluded.
Secondly, we did not evaluate the visual analog scale score and migraine-related disability. In addition, duration of follow up was relatively short. However, our study also has strong points, as it is one of the first studies that evaluated the duration of BoNTA efficiency over the course of three months.

In conclusion, BoNTA treatment was effective in pain control and reduction of analgesic use in chronic migraine patients. However, the efficiency duration was not as long as it is thought to be in clinical practice. From the 3rd month onwards, an increase in pain and painkiller use was seen. Therefore, future studies with additional doses or additional methods would shed light on the treatment of chronic migraine with BoNTA.

\section{ACKNOWLEDGEMENTS}

The authors thank The Turkish Neurological Society for their support.

\section{References}

1. Sengul Y, Sengul HS, Bakim B, Yucekaya SK, Yucel S, Akgun M. Sleep disturbances and excessive daytime sleepiness in migraine: a comparison between comorbidities and disability. Sleep Biol Rhythms. 2015 Jan;13(1):76-84. https://doi.org/10.1111/sbr.12087

2. Lipton RB, Bigal ME. Migraine: epidemiology, impact, and risk factors for progression. Headache. 2005 Apr;45 Suppl 1:S3-S13. https://doi. org/10.1111/j.1526-4610.2005.4501001.x

3. Headache Classification Committee of the International Headache Society The international classification of headache disorders, 3rd edition (beta version). Cephalalgia. 2013 Jul;33(9):629-808. https:// doi.org/10.1177/0333102413485658

4. Lipton RB, Stewart WF. Migraine in the United States:a review of epidemiology and health care use. Neurology. 1993 Jun;43(6 Suppl 3):S6-10.

5. Leonardi M, Raggi A, Ajovalasit D, Bussone G, D’Amico D. Functioning and disability in migraine. Disabil Rehabil. 2010;32 Suppl 1:S23-32. https://doi.org/10.3109/09638288.2010.511687

6. Natoli JL, ManackA, Dean B, Butler Q, Turkel CC, Stovner L, et al. Global prevalence of chronic migraine: a systematic review. Cephalalgia. 2010 May;30(5):599-609. https://doi.org/10.1111/j.1468-2982.2009.01941.x

7. Martins IP, Gouveia RG, Parreira E. Kinesiophobia in migraine. J Pain. 2006 Jun; 7(6):445-51. https://doi.org/10.1016/j.jpain.2006.01.449

8. Adams AM, Serrano D, Buse DC, Reed ML, Marske V, Fanning KM, et al. The impact of chronic migraine:The Chronic Migraine Epidemiology and Outcomes (CaMEO) Study methods and baseline results. Cephalalgia. 2015 Jun;35(7):563-78. https://doi.org/10.1177/0333102414552532

9. Dodick DW, Turkel CC, DeGryse RE, Aurora SK, Silberstein SD, Lipton $\mathrm{RB}$, et al. OnabotulinumtoxinA for treatment of chronic migraine: pooled results from the double-blind, randomized, placebocontrolled phases of the PREEMPT clinical program. Headache. 2010 Jun;50(6):921-36. https://doi.org/10.1111/j.1526-4610.2010.01678.x

10. Aoki KR. Pharmacology and immunology of botulinum neurotoxins. Int Ophthalmol Clin. Summer 2005;45(3):25-37. https://doi. org/10.1097/01.iio.0000167167.10402.74

11. Saper JR, Mathew NT, Loder EW, DeGryse R, VanDenburgh AM. BoNTA-009 Study Group. A double-blind, randomized, placebocontrolled comparison of botulinum toxin type a injection sites and doses in the prevention of episodic migraine. Pain Med. 2007 Sep;8(6):478-85. https://doi.org/10.1111/j.1526-4637.2006.00168.x
12. Elkind AH, O'Caroll P, Blumenfeld A, DeGryse R, Dimitrova R, BoNTA-024-026-036 Study Group. A series of three sequential, randomized, controlled studies of repeated treatments with botulinum toxin type A for migraine prophylaxis. J Pain. 2006 Oct;7(10):688-96. https://doi.org/10.1016/j.jpain.2006.03.002

13. Zidan A, Roe C, Burke D, Mejico L. Onabotulinumtoxin A wear-off in chronic migraine, observational cohort study. $J$ Clin Neurosci. 2019 Nov;69:237-40. https://doi.org/10.1016/j. jocn.2019.07.043

14. Ruscheweyh R, Athwal B, Gryglas-Dworak A, Frattale I, Latysheva N, Ornello R, et al. Wear-off of OnabotulinumtoxinA effect over the treatment interval in chronic migraine: a retrospective chart review with analysis of headache diaries. Headache. 2020 Sep;60(8):1673-82. https://doi.org/10.1111/ head.13925

15. Quintas S, García-Azorín D, Heredia P, Talavera B, Gago-Veiga AB, Guerrero ÁL. Wearing off response to OnabotulinumtoxinA in chronic migraine: Analysis in a series of 193 patients. Pain Med. 2019 Sep;20(9):1815-21. https://doi.org/10.1093/pm/pny282

16. Masters-Israilov A, Robbins MS. OnabotulinumtoxinA wear-off phenomenon in the treatment of chronic migraine. Headache. 2019 Nov;59(10):1753-61. https://doi.org/10.1111/head.13638

17. Khan FA, Mohammed AE, Poongkunran M, Chimakurthy A, Pepper M. Wearing off effect of OnabotulinumtoxinA near the end of treatment cycle for chronic migraine: a 4-year clinical experience. Headache. 2020 Feb;60(2):430-40. https://doi. org/10.1111/head.13713

18. Aurora SK, Dodick DW, Turkel CC, DeGryse RE, Silberstein SD, Lipton RB, et al. OnabotulinumtoxinA for treatment of chronic migraine: Results from the double-blind, randomized, placebo-controlled phase of the PREEMPT 1 trial. Cephalalgia. 2010 Jul;30(7):793-803. https://doi.org/10.1177/0333102410364676

19. Diener HC, Dodick DW, Aurora SK, Turkel CC, DeGryse RE, Lipton $\mathrm{RB}$, et al. OnabotulinumtoxinA for treatment of chronic migraine: Results from the double-blind, randomized, placebo-controlled phase of the PREEMPT 2 trial. Cephalalgia. 2010 Jul;30(7):804-14. https://doi.org/10.1177/0333102410364677 